\title{
ALTERAÇÕES NAS CARACTERÍSTICAS QUÍMICAS DA MADEIRA COM A SUBSTITUIÇÃO DO K POR Na EM PLANTAÇÕES DE EUCALIPTO ${ }^{1}$
}

\author{
Carlos Roberto Sette Jr², Mario Tomazello Filho³, Francides Gomes da Silva Jr e Jean Paul Laclau ${ }^{5}$
}

RESUMO -Visando à substituição parcial do potássio pelo sódio na fertilização das plantações florestais, avaliou-se o efeito da ação isolada desses nutrientes nas características químicas da madeira juvenil de Eucalyptus grandis. Foram plantadas árvores no espaçamento de $2 \mathrm{~m}$ x $3 \mathrm{~m}$ e aplicados $116 \mathrm{~kg} \mathrm{ha}^{-1}$ de $\mathrm{K}$ e 68,5 kg ha-1 de $\mathrm{Na}$. Árvores de eucalipto foram cortadas do $1^{\circ}$ ao $4^{\circ}$ ano após o plantio, em cada tratamento de fertilização, sendo seccionados discos de madeira em diferentes alturas do tronco e demarcados os anéis de crescimento anuais, estimados por um modelo de perfil do tronco. Amostras representativas de cada anel de crescimento, posição longitudinal e tratamento foram obtidas para determinação dos teores de lignina, holocelulose e extrativos. As árvores de eucalipto que receberam aplicação de potássio e de sódio não sofreram alterações significativas nas característias químicas, indicando que a substituição do K pelo Na na fertilização de plantações florestais de eucalipto pode ser adotada sem que as características químicas da madeira juvenil presente em árvores jovens se alterem. As avaliações anuais indicaram redução significativa dos teores médios de lignina e extrativos totais e aumento dos terores médios de holocelulose com a elevação da idade das árvores. Consistentes alterações nos teores dos componentes químicos do lenho por posição longitudinal e por anel de crescimento foram observadas.

Palavras-chave: Fertilização; Qualidade da Madeira; Modelo de Perfil do Tronco.

\section{CHANGES IN CHEMICAL PROPERTIES OF WOOD WITH SUBSTITUTION OF K BY Na IN EUCALYPTUS PLANTATIONS}

\begin{abstract}
With the purpose of partial substitution of potassium by sodium in the forest plantations fertilization, the effect of the isolated performance of these nutrients on the chemical properties of young wood in Eucalyptus grandis trees was evaluated. Trees were planted at a $2 \mathrm{mx} 3 \mathrm{~m}$ spacing and $116 \mathrm{~kg} \cdot \mathrm{ha}^{-1}$ of K and $68.5 \mathrm{~kg} . \mathrm{ha}^{-1}$ of Na were applied to them. Eucalypt trees were cut down from the 1st to the 4th year after planting in each fertilization treatment, being sectioned disks of wood in different positions of the trunk and marked the annual growth rings, estimated by a stem profile model. Representative samples of each annual ring, longitudinal position and treatment were obtained for determining the lignin, holocellulose and extractives. Eucalyptus trees that received application of potassium and sodium did not change significantly in chemical properties, indicating that the substitution of $\mathrm{K}$ by $\mathrm{Na}$ in fertilization of Eucalyptus plantations can be adopted without the alteration of the chemical properties in the young wood in the young trees. Annual evaluations indicated a significant reduction in average content of lignin and total extractives and an increase in average contents of holocellulose with increasing age of the trees. Consistent changes in the levels of chemical properties of wood for the longitudinal and ring growth were observed.
\end{abstract}

Keywords: Fertilization; Wood quality; Stem profile model.

\footnotetext{
${ }^{1}$ Recebido em 07.11.2013 aceito para publicação em 29.04.2014.

${ }^{2}$ Departamento de Engenharia Florestal, Escola de Agronomia, Universidade Federal de Goiás, GO, Brasil. E-mail: $<$ crsettejr@hotmail.com>.

${ }^{3}$ Departamento de Ciências Florestais, Escola Superior de Agricultura Luiz de Queiroz, Universidade de São Paulo, SP, Brasil. E-mail:<mtomazel@usp.br>.

${ }^{4}$ Departamento de Ciências Florestais, Universidade de São Paulo, SP, Brasil. E-mail: <fgomes@usp.br>.

${ }^{5}$ CIRAD, França. E-mail: <laclau@cirad.fr>.
} 


\section{INTRODUÇÃO}

A possibilidade de substituição total ou parcial do potássio por sódio na fertilização das plantações florestais é de interesse prático e científico, uma vez que as principais fontes de $\mathrm{K}$ possuem $\mathrm{Na}$ em sua composição (MARSCHNER, 1995), e o uso desses minerais representa em economia de energia requerida no processo de purificação, o que permite redução no preço dos fertilizantes potássicos. Particularmente no Brasil, que é o terceiro consumidor mundial, em 2011 foram utilizadas cerca de 8,5 milhões de toneladas de cloreto de potássio, sendo 91\%, ou seja, 7,6 milhões de toneladas importadas, gerando custos da ordem de US\$ 3,4 bilhões anuais (ANDA, 2012).

Apesar de o Brasil ser um dos maiores consumidores de fertilizantes, incluindo o potássio, ele não figura entre os principais produtores, ficando suscetível às oscilações dos preços internacionais, com reflexos diretos nos custos da implantação florestal e, consequentemente, no preço da madeira. Nesse sentido, a substituição total ou parcial do K por Na diminuiria a dependência de fertilizantes importados, reduzindo os custos de implantação das florestas de eucalipto e, em consequência, os custos finais da madeira. Nesse cenário, é fundamental a determinação dos efeitos da aplicação do potássio e do sódio na qualidade da madeira de eucalipto em plantações florestais, visando à futura substituição dos elementos.

Da mesma forma, no Brasil as áreas em cultivo são, em sua maioria, estabelecidas em regiões de baixa fertilidade, particularmente pobres em K (GONÇALVES et al., 2004). Por consequência, a compreensão dos efeitos da disponibilidade potássica sobre o funcionamento dos povoamentos de eucalipto, especialmente quanto às características químicas da madeira, torna-se determinante. Embora os estudos mostrem que a fertilização promova aumentos nas taxas de crescimento das plantações florestais de eucalipto, pouco se conhece sobre os seus efeitos nas características químicas da madeira (SILVEIRA; MALAVOLTA, 2003), especialmente a ação isolada dos nutrientes (SETTE JR. et al., 2010). As alterações nas condições de crescimento, devido à aplicação de fertilizantes, são, normalmente, relacionadas a alterações na qualidade da madeira, especialmente sobre as características anatômicas e físico-químicas (LARSON, 1969).

Revista Árvore, Viçosa-MG, v.38, n.3, p.569-578, 2014
Para determinação da qualidade da madeira de eucalipto, especialmente para os usos na produção de polpa celulósica e papel e de carvão vegetal, as características químicas como os teores de holocelulose, lignina e extrativos têm sido considerados os mais relevantes e normalmente influenciam os processos de produção e a qualidade da polpa e do carvão produzidos (WALLIS et al., 1996).

Nos últimos anos, interesse especial tem sido dado para determinação do efeito do K na atividade cambial e desenvolvimento das árvores, mostrando alta relação entre a nutrição com potássio e a formação da madeira (FROMM, 2010), tornando-se fundamental a sua caracterização em árvores de eucalipto submetidas aos efeitos desse macronutriente. Entretanto, poucos trabalhos têm sido desenvolvidos para avaliar o efeito do Na no crescimento e qualidade da madeira em plantações florestais de eucalipto, destacando-se os desenvolvidos por Sette JR. et al. (2009 e 2010).

Este trabalho teve como objetivo principal avaliar o efeito da ação isolada da adubação potássica e sódica nas características químicas da madeira de E. grandis, visando à futura substituição parcial do K por Na.

\section{MATERIAL E MÉTODOS}

\subsection{Caracterização da área de estudo}

O experimento foi instalado em abril de 2006, na Estação Experimental de Ciências Florestais de Itatinga, SP, do Departamento de Ciências Florestais da ESALQ/ USP, localizada a $23^{\circ} 10^{\prime} \mathrm{S}$ e $48^{\circ} 40^{\prime} \mathrm{W}$, com $857 \mathrm{~m}$ de altitude. O clima da região é caracterizado como mesotérmico úmido (Cwa), segundo Köeppen, com precipitação média anual de $1.400 \mathrm{~mm}$ e temperatura média de $16,2{ }^{\circ} \mathrm{C}$ e $28,6{ }^{\circ} \mathrm{C}$ nos meses mais frios e nos mais quentes, respectivamente. O solo é do tipo Latossolo Vermelho-Amarelo distrófico de textura média (200 g kg-1 de argila), com a litologia composta por arenito, formação Marília, do Grupo Bauru.

\subsection{Delineamento experimental}

O ensaio foi implantado em delineamento experimental em blocos casualizados com três tratamentos e quatro blocos. Os tratamentos foram definidos por três doses de fertilizantes, sendo (i) controle, sem aplicação de K e Na; (ii) aplicação de 3,0 kmol ha-1 de K (116 kg ha-1 de K na forma de $\mathrm{K}_{2} \mathrm{O}$ ), usada em solos semelhantes por empresa florestadora 
da região, constituindo-se em importante referência; e (iii) aplicação de 3,0 kmol ha-1 de $\mathrm{Na}\left(68,5 \mathrm{~kg} \mathrm{ha}^{-1}\right.$ de $\mathrm{Na}$ na forma de $\mathrm{NaCl}$ ), aplicados em três diferentes momentos ao longo do primeiro ano (1/3 no plantio, $1 / 3$ aos seis meses e $1 / 3$ aos 12 meses). Os tratamentos receberam, também, $80 \mathrm{~kg}$ de $\mathrm{P}_{2} \mathrm{O}_{5}, 45 \mathrm{~kg}$ de $\mathrm{N}\left(\mathrm{NH}_{4}(\mathrm{SO} 4)_{2}\right)$ e $45 \mathrm{~kg}$ de FTE (BR-12) $\mathrm{ha}^{-1}$, como fonte de micronutrientes.

Cada parcela foi constituída de 81 árvores, não sendo consideradas as duas linhas de bordadura, para evitar a influência dos tratamentos de fertilização das parcelas adjacentes. Na área de implantação do projeto de pesquisa, foram distribuídos no solo, antes do plantio, $2.000 \mathrm{~kg} \mathrm{ha}^{-1}$ de calcário dolomítico, a lanço e sem incorporação.

\subsection{Seleção e coleta das amostras}

Foram selecionadas cinco árvores de eucalipto, representativas da classe de área basal média, por tratamento de fertilização (controle, potássio e sódio) e por idade (12, 24, 36 e 48 meses após o plantio), em um total de 60 árvores amostradas. As árvores de eucalipto foram cortadas e desramadas, bem como tiveram seus discos do lenho seccionados em cinco posições ao longo do tronco (base, 3, 6, 9 e 12 m, de acordo com a altura total da árvore), para as determinações das características químicas do lenho.

\subsection{Demarcação dos anéis de crescimento anuais}

O crescimento praticamente contínuo do tronco das árvores de eucalipto durante as estações do ano induz à formação de lenho homogêneo, com camadas ou anéis de crescimento anuais pouco distintos (SETTE JR. et al., 2013). Os anéis de crescimento no lenho das árvores de eucalipto, próximo à casca (Figura 1), não correspondem à idade das árvores, sendo necessário demarcar a localização dos anéis anuais de crescimento/ idade cambial de formação do lenho. Dessa forma, para avaliar as características químicas da madeira por anel de crescimento anual, foi realizada a demarcação (Figura 1), estimada por um modelo de perfil do tronco, nos discos de lenho cortados nas quatro idades (12, 24, 36 e 48 meses) e em diferentes posições longitudinais (base, 3, 6, 9 e $12 \mathrm{~m}$, de acordo com a altura total).

O resultado da mensuração da circunferência do tronco sem casca de oito árvores de eucalipto/ tratamento, a cada $1 \mathrm{~m}$ no sentido longitudinal do tronco (diâmetro mínimo de $2 \mathrm{~cm})$, realizada anualmente ( $1^{\circ}$,

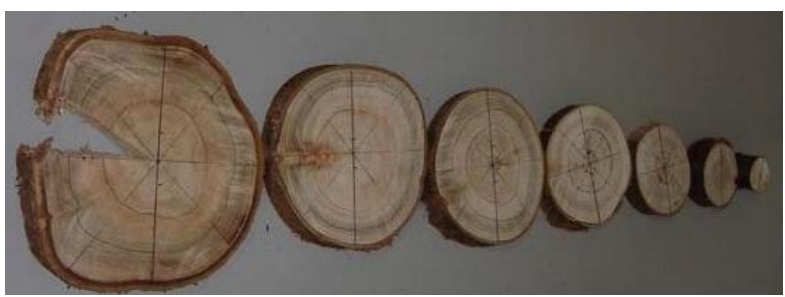

Figura 1 - Demarcação dos anéis de crescimento anuais nas seções transversais em diferentes posições longitudinais do lenho das árvores de eucalipto aos 48 meses.

Figure 1-Markings of the annual growth rings in cross sections in different longitudinal positions of eucalypt trees wood at 48 months.

$2^{\circ}, 3^{\circ}$ e $4^{\circ}$ anos) por Laclau et al. (2010), foi utilizado na predição do diâmetro do tronco sem casca $\left(d_{z}\right)$ em cada posição longitudinal (z), utilizando a equação 1.

$$
\frac{d_{z}}{d_{1,3}}=\left[\frac{H-z}{H-1,3}\right]^{\left(P 1+P 2 \exp \left(\frac{P 3 z}{P 2 H}\right)\right)}+\varepsilon
$$

em que o erro ( $\varepsilon$ ) segue distribuição normal, e $\mathrm{d}_{1,3}$ e H são diâmetros sem casca na altura de 1,3 m e altura total da árvore, respectivamente. Os parâmetros P1, P2 e P3 foram ajustados através da mensuração dos diâmetros do tronco sem casca nas quatro idades (12, 24, 36 e 48 meses) de corte das árvores. Os modelos mostraram baixo desvio-padrão residual e distribuição dos resíduos não tendenciosa (imparcial). As mensurações anuais do DAP e da altura total das árvores combinadas com a equação 1 possibilitaram estimar o diâmetro sem casca do tronco das árvores das quatro idades em cada posição longitudinal. Dessa forma, os anéis de crescimento anuais foram demarcados na seção transversal dos discos de lenho nas diferentes posições longitudinais do tronco (Figuras 1). Amesma metodologia para a demarcação dos anéis de crescimento anuais, através da combinação de inventários florestais anuais e modelo de perfil do tronco, foi utilizada por Laclau et al. (2001) e Sette Jr. et al. (2013) para avaliar a mobilidade de nutrientes no lenho de árvores de eucalipto.

\subsection{Determinação das características químicas}

As análises das características químicas do lenho foram realizadas no Laboratório de Química, Celulose e Energia (LQCE) da Escola de Agricultura "Luiz de Queiroz”, ESALQ/USP. Os discos de madeira cortados nas idades de 12, 24, 36 e 48 meses, em diferentes posições longitudinais e nos três tratamentos de fertilização,

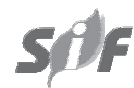

Revista Árvore, Viçosa-MG, v.38, n.3, p.569-578, 2014 
passaram pelo procedimento da demarcação das camadas de crescimento anuais, conforme descrito no subitem 2.4. Amostras do lenho, representativas de cada anel de crescimento anual, foram obtidas de cada disco, com o uso de equipamento de serra-fita, totalizando 420 amostras, para posterior moagem em moinho tipo Willey e classificação para obtenção da fração 40/60 mesh recomendada pelas normas TAPPI T 264 cm-97 (1997) e TAPPI T 257 cm-85 (1985) para análise química.

Posteriormente, esse material foi levado para a câmara de climatização com temperatura de $20 \pm 3{ }^{\circ} \mathrm{C}$ e umidade relativa de $65 \pm 2 \%$, permanecendo nessa condição para a homogeneização da umidade. Das amostras moídas, foram determinados os teores de lignina solúvel e insolúvel, sendo o teor de lignina total o somatório desses dois teores, conforme a norma TAPPI T 222 om-98 (1998/1999), e dos teores de extrativos totais e holocelulose, de acordo com o preconizado nas normas TAPPI T 204 cm-97 (1998/1999) e TAPPI T 19 om-54 (2002), respectivamente.

\subsection{Análise estatística}

Na análise estatística dos resultados, foi aplicado o programa JMP (SAS, 1997), sendo aferidos os outliers e a heterogeneidade da variância. Foi utilizada a análise de variância (ANOVA) nos resultados, quando se verificou o efeito dos tratamentos, da idade e das posições longitudinais do tronco e das interações, sendo aplicado o teste de Tukey ajustado a 95\% de probabilidade.

\section{RESULTADOS}

Os componentes químicos do lenho não apresentaram diferenças significativas entre os tratamentos de fertilização (Tabela 1). Apesar do efeito não significativo, as árvores do tratamento com aplicação de K e Na apresentaram teores de lignina e extrativos totais ligeiramente superiores aos das árvores do tratamento controle, com 28,2-28,4\% e 3,7-3,9\%, respectivamente. Os teores médios de holocelulose encontrados no lenho das árvores foram de 69,8\% no tratamento-controle, 68,6\% na aplicação de K e 69,2\% na aplicação de Na.

As avaliações dos componentes químicos do lenho, aos 12, 24, 36 e 48 meses, indicaram redução significativa dos teores médios de lignina (30\% para $26,4 \%$ ) e extrativos totais (5,1\% para $2,1 \%$ ) e incremento dos teores médios de holocelulose (67,6 para 70,8\%) com o aumento da idade das árvores (Tabela 2).

Com relação às camadas ou anéis de crescimento anuais, houve redução nos teores de lignina da região interna (anel 1) para a externa do lenho (anel 4) das árvores de eucalipto nos tratamentos controle (29,1-26,5\% para 25,7\%), com aplicação de K (30,5-

Tabela 1 - Características químicas do lenho de eucalipto por tratamento de fertilização.

Table 1 - Chemical properties of eucalypt wood per fertilization treatment.

\begin{tabular}{|c|c|c|c|}
\hline Tratamentos & Lignina total (\%) & Holocelulose (\%) & Extrativos totais (\%) \\
\hline Controle & 27,8 a $(1,28)$ & $69,8 \quad$ a $(0,98)$ & 2,8 a $(1,65)$ \\
\hline $\mathrm{K}$ & 28,4 a $(1,54)$ & 68,6 a $(1,16)$ & 3,9 a $(1,63)$ \\
\hline $\mathrm{Na}$ & 28,2 a $(1,40)$ & 69,2 a $(1,19)$ & 3,7 a $(0,71)$ \\
\hline
\end{tabular}

Médias seguidas de desvio-padrão. Médias seguidas da mesma letra, na coluna, não diferem entre si, pelo teste de Tukey $(\mathrm{p}<0,05 \%)$.

Médias seguidas de desvio-padrão. Médias seguidas da mesma letra na coluna não diferem entre si, a 5\% de probabilidade, pelo teste de Tukey.

Tabela 2 - Características químicas do lenho de eucalipto por idade.

Table 2 - Chemical properties of eucalypt wood per age.

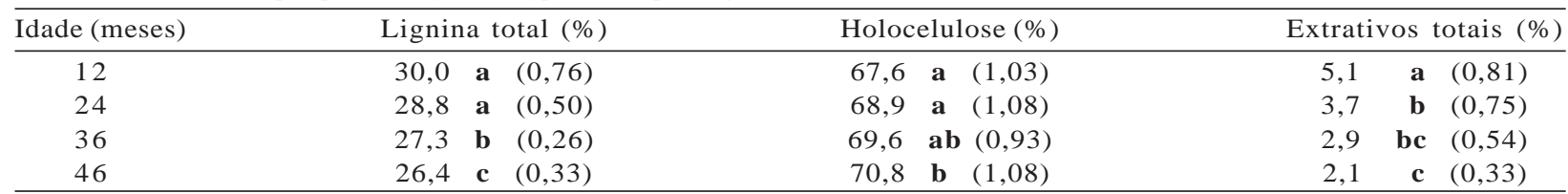

Médias seguidas de desvio-padrão. Médias seguidas da mesma letra, na coluna, não diferem entre si, pelo teste de Tukey $(\mathrm{p}<0,05 \%)$.

Means followed by standard deviation. Means followed by the same letter in the colmn do not differ from each other at $5 \%$ probability by Tukey's test.

Revista Árvore, Viçosa-MG, v.38, n.3, p.569-578, 2014 
$28,3 \%$ para $25,9 \%)$ e de $\mathrm{Na}(30,3-28,3 \%$ para $26,1 \%)$. Da mesma forma, os teores de extrativos totais sofreram redução do anel 1 para o anel 4, na ordem de 63-70\%, 47-60\% e 37-70\%, nos tratamentos controle, K e Na, respectivamente (Figura 2 ).

Diferentemente do observado nas demais características químicas, os teores de holocelulose aumentaram da região interna, próxima à medula, para a externa, próxima à casca (Figura 2), com mais evidência nos tratamentos controle e $\mathrm{K}$.

A variação dos componentes químicos da madeira nas diferentes posições longitudinais do tronco das árvores, nos quatro primeiros anos após o plantio, é apresentada na Figura 3, com efeito estatisticamente significativo. O modelo de variação longitudinal, comum nas quatro idades avaliadas, caracteriza-se pelo
Controle
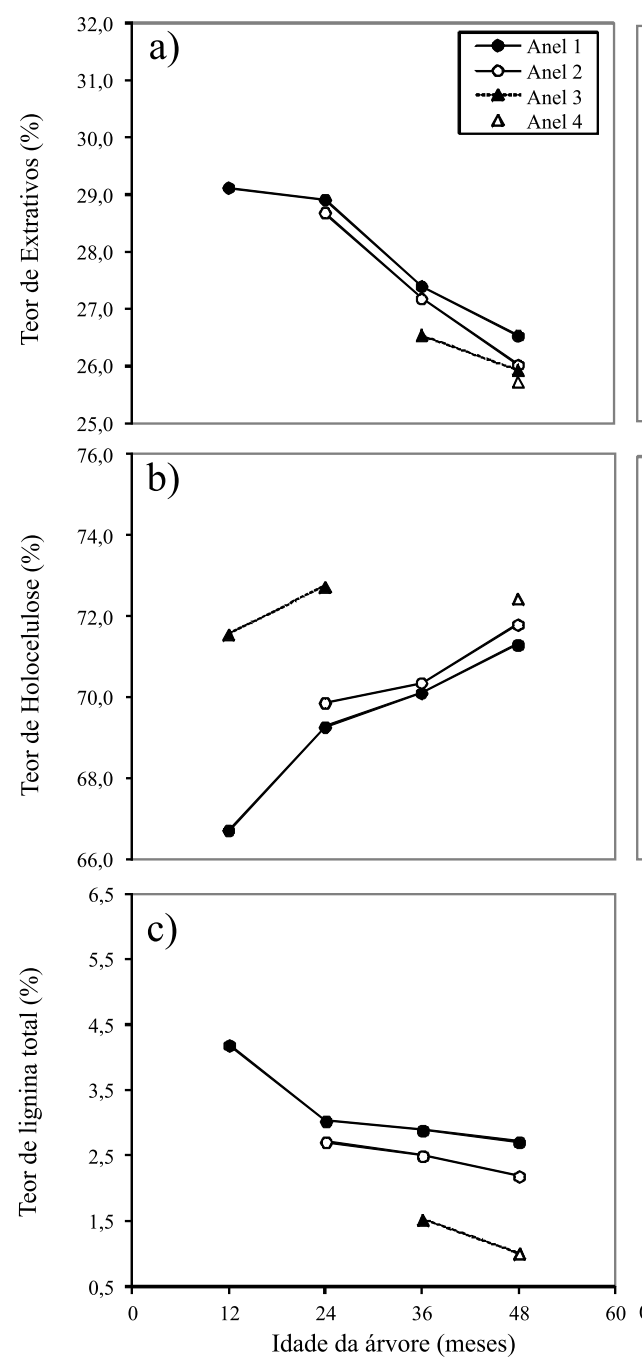

$\mathbf{K}$
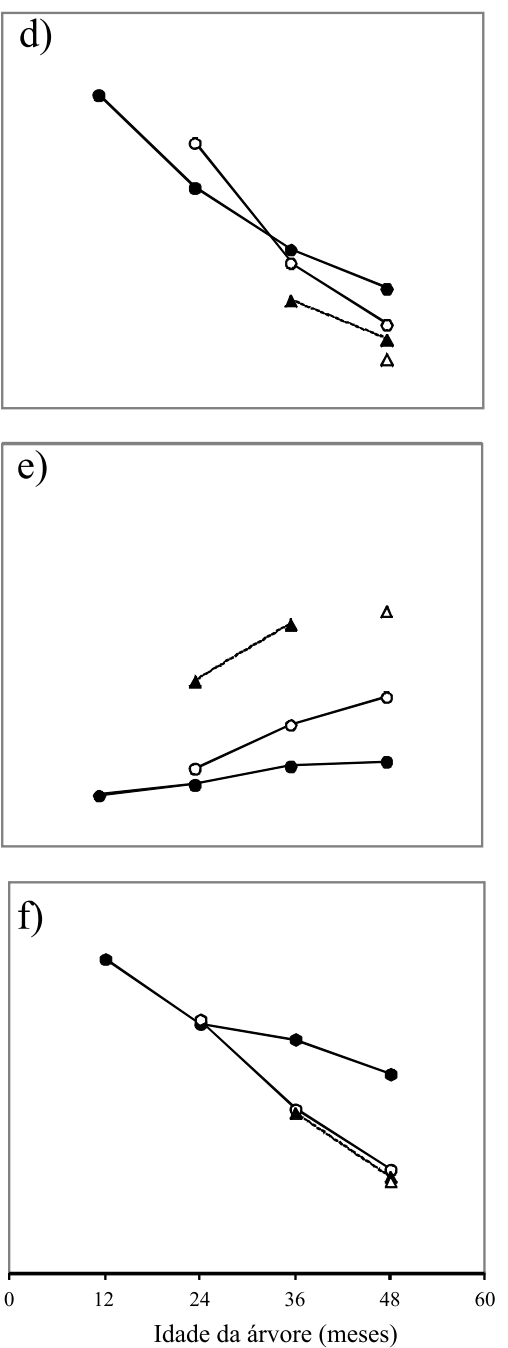

Na
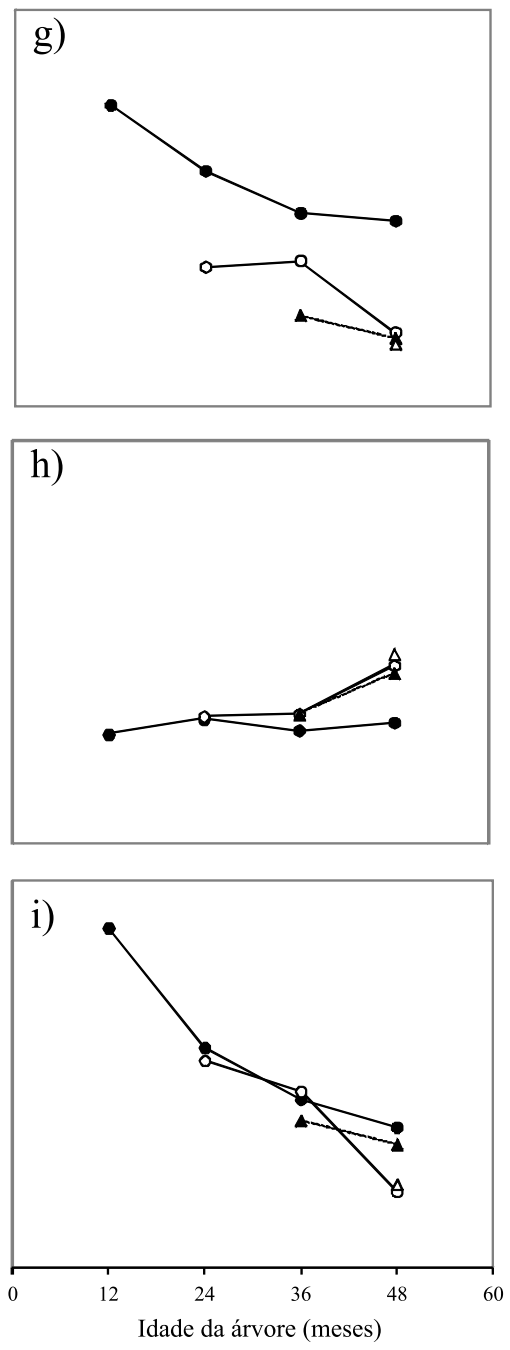

Figura 2 - Alterações nos teores de lignina, holocelulose e extrativos por anel de crescimento nos quatro primeiros anos após plantios nos tratamentos controle (a, b e c, respectivamente), K (d e f, respectivamente) e Na (g, h e i, respectivamente).

Figure 2 - Changes in contents of lignin, holocellulose, extractive per annual rings over the first 4 years after planting in control treatments ( $a, b$ and c, respectively), K (d and $f$, respectively), and $N a$ ( $g, h$ and $i$, respectively). 
decréscimo/estabilização da base-9m dos teores de Lignina (26,9-28,7\% para 24,8-25,9\%) e extrativos totais (2,5-4,3\% para 1,5-29 2,4\%) e aumento dos teores de holocelulose (68,5-69,4 para 72,64\%). Nos três parâmetros químicos, na idade de 48 meses foram observados aumento (lignina e extrativos) e redução (holocelulose) dos teores na posição próxima à extremidade do tronco, indicando haver correlação negativa, ou seja, quanto maiores os teores de lignina e extrativos, menores os teores de holocelulose.

\section{DISCUSSÃO}

Os componentes químicos do lenho não apresentaram diferenças significativas entre os tratamentos de fertilização (Tabela 1). Esse resultado indica que, apesar de a aplicação da fertilização potássica

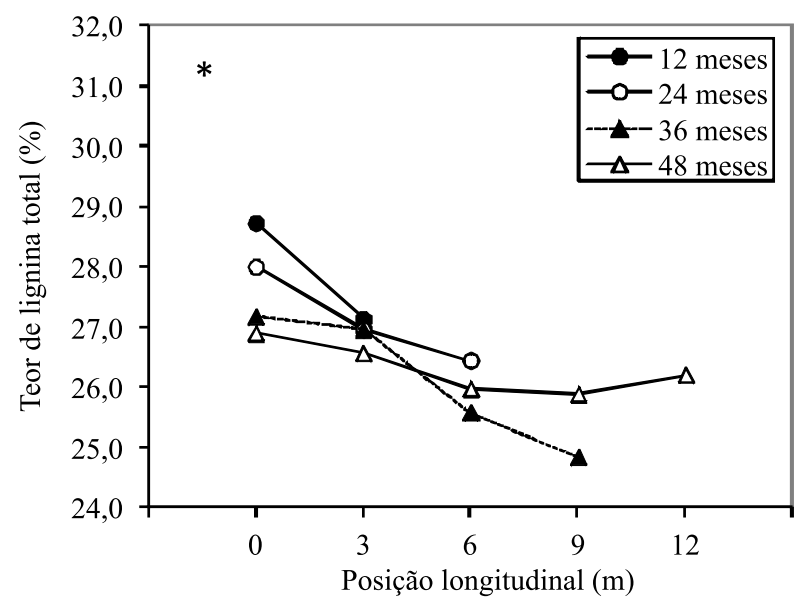

e sódica promover significativos aumentos nas taxas de crescimento em relação às árvores-controle - DAP médio aos 48 meses de 12,3; 11,4; e 10,1 cm, respectivamente, nos três tratamentos, apontados pelo trabalho realizado na mesma área experimental por Sette Jr. et al. (2010) -, não são evidenciadas alterações nas concentrações desses componentes. Da mesma forma, sugerem que a substituição do K pelo Na na fertilização de plantações florestais de eucalipto pode ser adotada sem que as características químicas, parâmetro importante de qualidade do lenho especialmente para usos da madeira na indústria de celulose e papel e na de carvão vegetal, se alterem.

Sette Jr. et al. (2009 e 2010) avaliaram, na mesma área experimental, a densidade da madeira e a taxa de crescimento em diâmetro do tronco das árvores de

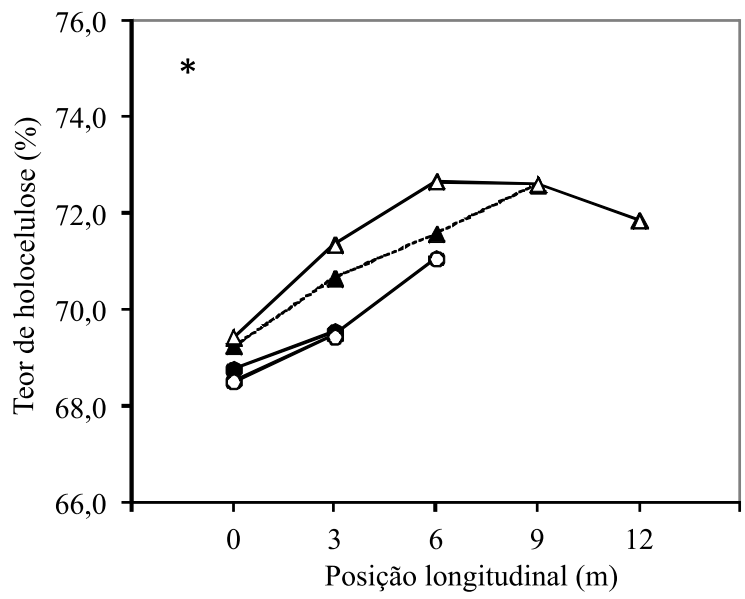

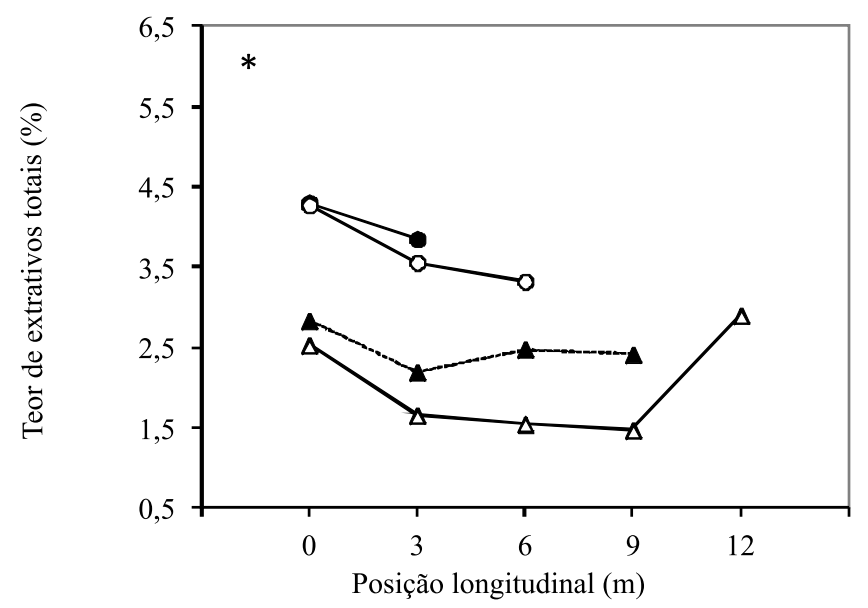

Figura 3 - Variação longitudinal dos teores de lignina total, holocelulose e extrativos totais por idade. *Significativo $(p<0,05)$. Figure 3 - Longitudinal variation of total lignin, holocellulose and total extractive contents per age. *Significant ( $p<0.05)$

Revista Árvore, Viçosa-MG, v.38, n.3, p.569-578, 2014 
eucalipto até a idade de 4 anos: a fertilização potássica e sódica não alterou a densidade, sendo observadas taxas de crescimento superiores às das árvores que não foram adubadas, com pequena vantagem daquelas que receberam $\mathrm{K}$. Cabe ressaltar que os parâmetros de qualidade e crescimento do lenho das árvores devem ser avaliados em idades mais avançadas, especialmente na idade de corte para essa espécie nos usos energéticos e para produção de celulose e papel, para que a substituição parcial do K pelo Na possa ser recomendada e adotada na implantação florestal. Apesar disso, informações como as apresentadas neste trabalho e em outros realizados na mesma área experimental e que avaliaram os efeitos da fertilização potássica e sódica na plantação florestal de eucalipto são importantes para a construção de uma série temporal que permite avaliar as alterações causadas pela adubação ao longo de toda a rotação do $E$. grandis até o seu corte final aos 7 anos.

Silveira e Malavolta (2003) determinaram os efeitos da aplicação do potássio nas características químicas no lenho juvenil de progênies E. grandis. Os materiais genéticos apresentaram respostas distintas para a concentração e quantidade de holocelulose no lenho em função da dose de K na solução nutritiva: a adição de potássio aumentou a concentração de holocelulose nas progênies 1 e 2. Barreiros et al. (2007) avaliaram o efeito da aplicação de lodo de esgoto tratado (0 a 40 t ha- 1 base seca) e uma dose de adubo mineral nos atributos químicos da madeira de E. grandis de árvores com 5 anos de idade: o lodo de esgoto não afetou os teores de celulose, lignina e extrativos da madeira. Assis (2013) estudou níveis de fertilização e seus efeitos nas características da madeira de híbridos de E. grandis x urophylla: o efeito da fertilização não afetou nenhuma das características químicas analisadas.

Apesar de não significativo, as árvores adubadas com K e Na apresentaram ligeiro aumento nos teores de lignina e extrativos e redução nos teores de holocelulose (Tabela 1). Segundo Vital (1990), a adubação pode ocasionar essa pequena alteração na qualidade da madeira, e Andrade et al. (1994) observaram aumento na concentração de extrativos em madeira de E. grandis, devido à aplicação de calcário. Por mais que os extrativos presentes na madeira sejam geralmente extraídos durante o processamento químico de polpação, altos teores podem ter efeitos significativos nas propriedades das polpas celulósicas, conduzindo, por exemplo, a baixos rendimentos e dificuldades no branqueamento e, ainda, podem causar danos em equipamentos nas fábricas de celulose, por serem substâncias potencialmente formadoras de pitch (GOMIDE et al., 2005). Da mesma forma, madeiras com altos teores de lignina podem exigir maior consumo de álcali durante a polpação, gerando maiores teores de sólidos para queima na caldeira, tendo papel econômico importante no processo de produção de polpa celulósica.

Os valores médios dos teores de holocelulose, lignina e extrativos foram de 69; 28,1; e 3,5\%, respectivamente, estando dentro da faixa esperada para o gênero Eucalyptus (TRUGILHO et al., 1996; SILVA et al., 2005; BASSA et al., 2007).

As avaliações dos componentes químicos do lenho, aos 12, 24, 36 e 48 meses, indicaram redução significativa dos teores médios de lignina e extrativos totais e incremento dos terores médios de holocelulose com o aumento da idade das árvores (Tabela 2). Os maiores teores de lignina e extrativos no lenho das árvores mais jovens (12 meses) e consequente redução até a idade de 48 meses estão relacionados com a maior proporção de madeira juvenil no lenho dessas árvores mais jovens, que é mais rica em lignina e extrativos do que a madeira de transição/adulta (Figura 2), conforme relatado por Trugilho et al. (1996).

A composição química do lenho de E. saligna avaliada por Trugilho et al. (1996), nas mesmas idades deste estudo (do $1^{\circ}$ ao $4^{\circ}$ ano após o plantio), variou significativamente, sendo observada queda nos teores de lignina e de extrativos e incremento nos teores de celulose com o aumento da idade da árvore. Da mesma forma, Morais (2008), avaliando o efeito de diferentes idades (do $1^{\circ}$ ao $8^{\circ}$ ano após o plantio), nas características químicas da madeira de clones de E. grandis e E. grandis $\mathrm{x}$ urophylla, obteve os mesmos resultados.

Resultados opostos foram relatados por Silva et al. (2005), que estudaram a variação da composição química na madeira de $E$. grandis, porém em idades mais avançadas (10, 14, 20 e 25 anos), em que os teores de extrativos e lignina aumentaram e o de holocelulose diminuiu com a idade.

Considerando que as características químicas da madeira estão sujeitas a grandes variações iniciais na madeira juvenil e tendendo a valores mais estáveis, na madeira adulta (TRUGILHO et al., 1996), recomenda-se a avaliação do lenho das árvores de E. grandis em

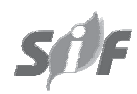

Revista Árvore, Viçosa-MG, v.38, n.3, p.569-578, 2014 
idades mais avançadas para determinar a variação das suas características e caracterizar a fase de sua estabilização (formação do lenho adulto), importante para a sua adequada utilização tecnológica.

Consistentes alterações nos teores dos componentes químicos do lenho por anel de crescimento para cada idade das árvores e tratamento de fertilização (Figura 2) confirmam que as camadas de crescimento anuais, pouco evidentes no lenho do eucalipto, foram corretamente demarcadas. Os modelos de variação dos componentes químicos do lenho indicaram redução nos teores de lignina e extrativos totais e aumento nos teores de holocelulose da região interna (anel 1) para a externa do lenho (anel 4) das árvores de eucalipto, sem influência ou diferença entre os tratamentos de fertilização (Figura 2). Essa constatação demonstra que a lignina e extrativos estão presentes em menores e, a holocelulose, em maiores teores no tecido do lenho fisiologicamente ativo, ou seja, no alburno e na madeira denominada transição entre a juvenil e a adulta, na região próxima à casca.

A avaliação da variação radial da densidade aparente por denditometria de raios $\mathrm{X}$ e do comprimento das fibras realizadas por Sette Jr. et al. (2010) no lenho das árvores de eucalipto amostradas na mesma área experimental demonstrou que até a idade de 4 anos as árvores de eucalipto apresentaram madeira juvenil, com início de transição para a adulta.

Na literatura são observados trabalhos que corroboram os resultados deste estudo, ou seja, menores teores de holocelulose e maiores teores de lignina e extrativos no lenho juvenil, mais próximo da medula (SJÖSTRÖN, 1981; ZOBEL; VAN BUIJTENEN, 1989). Nesse sentido, Severo et al. (2006) avaliaram a composição química da madeira de Corimbia citriodora no sentido medula-casa: o teor de lignina é superior e o de holocelulose, inferior no lenho juvenil. A consistência de variação dos teores das características químicas no lenho, similar nos três tratamentos de fertilização (Figura 2), demonstra que o efeito do K e $\mathrm{Na}$, na avaliação das plantas jovens de eucalipto, é praticamente nulo.

O modelo de variação longitudinal das características químicas do lenho indicou maiores concentrações de lignina e extrativos na base e tendência de redução em direção ao topo, exceto na idade de 48 meses, cujas árvores apresentaram estabilização/aumento desses teores nos discos de madeira coletados na posição de 9 e 12 m de altura. Entretanto, os resultados dos teores de holocelulose apresentaram comportamento diferenciado, ou seja, com padrão de acréscimo das concentrações da porção basal até as porções do tronco mais altas, tendendo à estabilização e redução das árvores com 48 meses.

Esse resultado evidencia a forte influência das raízes e da copa nos constituintes químicos, recomendando-se a utilização das regiões intermediárias do tronco para a produção de pasta celulósica, a qual é mais indicada em função dos menores teores observados. Os dados indicaram, ainda, que o comportamento dos constituintes químicos da madeira é inversamente proporcional, ou seja, enquanto os teores de lignina e extrativos, de maneira geral, decrescem no sentido base-topo, os de holocelulose aumentam (Figura 3). A correlação negativa entre os teores de celulose e lignina foi também observada por Trugilho et al. (1996).

Silva et al. (2005), estudando a variação longitudinal da composição química da madeira de E. grandis, verificaram que os teores de extrativos e lignina foram maiores nos discos próximos da base e que o teor de holocelulose apresentou maiores concentrações nos discos retirados nas regiões superiores do tronco, corroborando os resultados apresentados neste estudo. Severo et al. (2006) avaliaram a composição química da madeira de $C$. citriodora no sentido base-topo e, segundo eles, os teores de lignina e de holocelulose são constantes e os de extrativo totais decrescem até a porção intermediária, tendendo a acréscimo até o topo.

\section{CONCLUSÕES}

As árvores de eucalipto que receberam aplicação de potássio e de sódio não sofreram alterações significativas nos teores de holocelulose, lignina e extrativos totais. A substituição do K pelo Na na fertilização de plantações florestais jovens de eucalipto pode ser adotada sem que as características químicas, parâmetro importante de qualidade da madeira, se alterem.

A idade das árvores e a posição de amostragem da madeira no tronco influenciaram significativamente a concentração dos teores de holocelulose, lignina e extrativos totais. 


\section{REFERÊNCIAS}

\author{
ASSOCIAÇÃO NACIONAL PARA DIFUSÃO DE \\ ADUBOS - ANDA. Anuário estatístico do \\ setor de fertilizantes 2011. São Paulo: \\ 2012. 178p.
}

ANDRADE, A. M. et al. Efeitos da fertilização mineral e da calagem do solo na produção e na qualidade da madeira de eucalipto. Revista Árvore, v.18, n.1. p.69-78, 1994.

ASSIS, C. O. Níveis de fertilização e seus efeitos no crescimento, nas

características da madeira e do carvão em clone de híbrido de Eucalyptus grandis x Eucalyptus urophylla 2013.150p. Tese (Doutorado em Ciências Florestais) - Universidade Federal de Lavras, Lavras, 2013.

BARREIROS, R. M. et al. Modificações na produtividade e nas características físicas e químicas da madeira de Eucalyptus grandis causadas pela adubação com lodo de esgoto tratado. Revista Árvore, v.31, n.1, p.103-111, 2007.

BASSA, A. G. M. C.; SILVA JUNIOR, F. G.; SACON, V. M. Misturas de madeira de Eucalyptus grandis x Eucalyptus urophylla e Pinus taeda para produção de celulose kraft através do Processo Lo-Solids. Science Forest, n.75, p.19-29, 2007.

FROMM, J. Wood formation of trees in relation to potassium and calcium nutrition. Physiology, v.30, p.1140-1147, 2010.

GOMIDE et al. Caracterização tecnológica, para produção de celulose, da nova geração de clones de Eucalyptus do Brasil. Revista Árvore, Viçosa, v.29, n.1, p129-137. 2005

GONÇALVES, J.L.M. et al. An evaluation of minimum and intensive soil preparation regarding fertility and tree nutrition. In: GONÇALVES, J.L.M.; BENEDETII, V., eds. Forest nutrition and fertilization. Piracicaba, IPEF, 2004. p.13-64

LACLAU, J. P. et al. Resposta do Eucalyptus grandis a adubação potássica e a substituição do potássio por sódio. 2010. 65p. (Relatório apresentado a Fundação de Amparo à Pesquisa do Estado de São Paulo - FAPESP).
LACLAU, J. P. et al. Dynamics of nutrient translocation in stemwood across an age series of a Eucalyptus Annals of Botany, v.88, p.10791092, 2001.

LARSON, P. R. Wood formation and the concept of wood quality. New Haven: Yale University, 1969. 54p.

MARSCHNER, H. Mineral nutrition of higher plants. 2.ed. London: Academic Press, 1995. 889p.

MORAIS, P. H. D. Efeito da idade da madeira de eucalipto na sua química e polpabilidade, e branqueabilidade e propriedades físicas da polpa. 2008. $149 \mathrm{f}$. Dissertação (Mestrado em Ciências Florestais) Universidade Federal de Viçosa, Viçosa, MG, 2008.

SAS Institute. SAS/STAT User's Guide: vertion 6.08. Cary: 1997. v.2. 846p.

SEVERO, E.T.D. et al. Composição química da madeira de Eucalyptus citriodora em função das direcções estruturais. Silva Lusitana, v.14, n.1, p.113-126, 2006.

SILVA, J. C et al. Influência da idade e da posição ao longo do tronco na composição química da madeira de Eucalyptus grandis. Revista Árvore, v.29, n.3, p.455-460, 2005.

SILVEIRA, R.L.V.A.; MALAVOLTA, E. Produção e características químicas da madeira juvenil de progênies de Eucalyptus grandis em função das doses de potássio na solução nutritiva. Scientia Forestalis, n.63, p.115-135, 2003.

SJÖSTRÖN, E. Wood chemistry. Nova York: Academic Press, 1981. 223p.

SETTE Jr., C.R. et al. Efeito da aplicação de potássio e sódio nas características do lenho de árvores de Eucalyptus grandis W Hill, aos 24 meses de idade. Revista Floresta, v.39, n.3, p.535-546, 2009.

SETTE Jr., C. R. et al. Crescimento em diâmetro do tronco das árvores de Eucalyptus grandis W. Hill. Ex. Maiden e relação com as variáveis climáticas e fertilização mineral. Revista Árvore, v.34, n.6, p.979-990, 2010.

Revista Árvore, Viçosa-MG, v.38, n.3, p.569-578, 2014 
SETTE Jr., C. R. et al. Source-driven remobilizations of nutrients within stem wood in Eucalyptus grandis plantations. Trees - Structure and Function, v.27, n.4, p.827-839, 2013

\section{TAPPI TECHNICAL DIVISIONS AND}

COMMITTEES. TAPPI test methods: T 257 cm-85: sampling and preparing wood for analysis. Atlanta: Tappi Technical Divisions and Committees, 1985. 5p.

TAPPI TECHNICAL DIVISIONS AND COMMITTEES - TAPPI test methods: T 264 cm-97: preparation of wood for chemical analysis. Atlanta: Tappi Technical Divisions and Committees, 1997. 3p.

TECHNICAL ASSOCIATION OF PULPAND PAPER INDUSTRY. Acid - insoluble lignin in wood and pulp: T222 om-98. Atlanta: 1998/1999

TECHNICALASSOCIATION OF PULP AND PAPER INDUSTRY. Solvent extractives of wood and pulp: T204 cm-97. Atlanta: 1998/1999.
TECHNICAL ASSOCIATION OF THE PULP AND PAPER INDUSTRY. T19 om-54:

Holocellulose in wood. Atlanta: 2002.

TRUGILHO, P. F.; LIMA, J. T.; MENDES, L. M. Influência da idade e das características físico-químicas e anatômicas da madeira de Eucalyptus saligna. Cerne, v.2, n.1, p.94-111, 1996.

VITAL, B. R. Reflexos da fertilização mineral na qualidade e na utilização da madeira. In:

BARROS, N. F.; NOVAIS, R. F. Relação soloeucalipto. Viçosa, MG: Folha de Viçosa, 1990. p.323-330.

WALLIS, A. F. A.; WEARNE, R. H.; WRIGHT, P. J. Analytical characteristics of plantation eucalypt woods relating to Kraft pulp yields. Appita Journal, v.49, n.6, p.427-432, 1996.

ZOBEL B.J.; van BUIJTENEN, J.P. Wood variation: its causes and control. New York: Springer-Verlag, 1989. 363p. 